\title{
'Rapid Scenario Planning' to Support a Regional Sustainability Transformation Vision: A Case Study from Blekinge, Sweden
}

\author{
Giles Thomson *, Henrik Ny@ , Varvara Nikulina ${ }^{\circledR}$, Sven Borén, James Ayers and Jayne Bryant \\ Department of Strategic Sustainable Development, Blekinge Institute of Technology (BTH), \\ 37179 Karlskrona, Sweden; henrik.ny@bth.se (H.N.); varvara.nikulina@bth.se (V.N.); sven.boren@bth.se (S.B.); \\ james.ayers@bth.se (J.A.); jayne.bryant@bth.se (J.B.) \\ * Correspondence: grt@bth.se
}

Received: 10 July 2020; Accepted: 20 August 2020; Published: 26 August 2020

check for updates

\begin{abstract}
This paper presents a case study of a transdisciplinary scenario planning workshop that was designed to link global challenges to local governance. The workshop was held to improve stakeholder integration and explore scenarios for a regional planning project (to 2050) in Blekinge, Sweden. Scenario planning and transdisciplinary practices are often disregarded by practitioners due to the perception of onerous resource requirements, however, this paper describes a 'rapid scenario planning' process that was designed to be agile and time-efficient, requiring the 43 participants from 13 stakeholder organizations to gather only for one day. The process was designed to create an environment whereby stakeholders could learn from, and with, each other and use their expert knowledge to inform the scenario process. The Framework for Strategic Sustainable Development (FSSD) was used to structure and focus the scenario planning exercise and its subsequent recommendations. The process was evaluated through a workshop participant survey and post-workshop evaluative interview with the regional government project manager to indicate the effectiveness of the approach. The paper closes with a summary of findings which will support those wishing to conduct similar rapid scenario planning exercises to inform policy planning for complex systems.
\end{abstract}

Keywords: strategic sustainable development; scenario planning; transdisciplinary; regional development; sustainability governance; sustainability transformation; urban planning

\section{Introduction}

Uncertainty caused by the complex interactions of the numerous 'grand challenges' of the Anthropocene makes visualizing and planning for unknown futures difficult. Yet government agencies and other organizations are routinely called upon to provide robust planning responses to ensure resilient, livable and sustainable societies. Scenario planning is increasingly seen as a useful strategic tool for preparing policy in times of uncertainty [1-3]. This paper describes a scenario workshop, and related activities designed to (i) envision alternative future(s) that could support more concrete subsequent planning [4], and (ii) improve stakeholder integration and knowledge sharing for a regional planning project that had sustainability at its core. The scenario approach was used to better understand the values and needs of the stakeholder participants within the previously agreed strategic direction of their respective organizations. The challenge was to make the most of the scarce time resource in busy professional's work lives, and provide a way to learn from, and with, each other. We are describing this process as 'rapid scenario planning' because, contrary to many scenario planning approaches, this case was designed to be agile and time-efficient so that the participants were required 
to gather for only one day. The authors hope that by sharing details of this case study, others will find our approach helpful, particularly if they are tasked with designing a time constrained workshop, comprising of diverse stakeholders, with uncertain planning outcomes and an aspiration to move strategically towards sustainability.

The paper has three objectives:

1. To describe the role of transdisciplinary research in this case study as applied to policy creation,

2. To evaluate the success of a 'rapid scenario planning' process to support a well-informed stakeholder group in an efficient workshop process, and

3. To offer recommendations to those seeking to design a similar process to inform sustainability transformation policy.

The following background section describes the rationale of the researchers for engaging in a transdisciplinary scenario process with the local government organizations.

\subsection{Background}

Society faces the immense socio-ecological challenge of both "decreasing ecosystem quality and increasing risk of tipping the biosphere into a state where it would be difficult or impossible to maintain the human civilization" [5] (p. 17). The increasing scale of human activity is having a profound impact on the natural environment [6], the imbalance between human-nature interactions is expressed in multiple environmental challenges such as water scarcity, epidemics, climate change-among many other persistent and complex challenges which threaten the viability and integrity of global societies [7]. Dominant societal models are unsustainable "as the results of ignorance of the consequences of consumption, inattention to human dependence on ecological realities" [8] (p. 860), which combined make staying within the safe operating space of planetary boundaries a global problem [9] and a challenge for all levels of government to manage, at national, regional and local levels due to their 'wicked' nature. 'Wicked problems,' developed in planning research by Rittel and Webber [10], are characterized as multidimensional, path-dependent and unpredictable in nature. Planning itself is complex, but it needs to additionally include the global, interconnected and uncertainty aspects surrounding planetary sustainability that compound pressure upon local planners, who must now consider their traditional planning role within a broader need for sustainability transformation. The sustainability challenge itself has even been identified as a 'super wicked' problem as it includes four further challenges to planners, which include that: time is running out, those seeking to end the problem are also causing it, there is no central authority for decision making, and that policies discount the future irrationally [11]. These create an immense contemporary crisis with little defined process to guide constructive future pathways. City and regional planners create policy that is highly impactful on human-nature interaction, yet rarely are they offered a reflective space to consider these implications [12].

Despite this, the pressure for sustainable transformation exists within all regional and municipal governments, because the local level plays a crucial role in facilitating the sustainability transformation needed to address multiple national and international agreements, such as the Paris Agreement [13], Agenda 2030 [14] and the New Urban Agenda [15]. The Agenda 2030 [14], Sustainable Development Goals (SDGs) were developed to help nations plan for sustainability, and regular assessments against the goals offer an indication of nation-state performance showing that some countries are doing better in terms of progress toward sustainability. For example, according a 2020 SDG assessment, Sweden is leading the world in progress toward the goals [16], but even Sweden is struggling to progress in certain areas. In 2019, the Swedish Climate Policy Council [17] highlighted that sustainability action is progressing too slowly to meet current national and international carbon reduction goals-particularly for transport and built environment sectors. It has been documented by others that there is a geographical unevenness of sustainability transformation processes [18], indeed within Sweden much sustainability innovation and infrastructure investment is focused on 
major population centers. For example, Blekinge receives relatively less rail investment from the central government than many other regions. Funding on some planned rail links (e.g., the Southeast Link in Blekinge) has been delayed numerous times while investment in other central projects around the bigger cities gets funding, and current plans for future investment in Swedish high-speed trains will not prioritize more remote regions like Blekinge. Unequal investment concentrated around the largest centers with regional areas lagging behind is not unusual [19], but it does pose a challenge for regional areas. This unequal power concentration and dispersion in multi-level governance shapes local agency for sustainability transitions and has been discussed in detail by others who indicate that insufficient coordination and other obstacles embedded in wider political-institutional contexts between the national, regional, and local planning efforts is a key factor behind the failure of many regions to meet high-level sustainability goals [20]. Yet regardless of their resources, all governments, large and small, are under pressure to transform towards greater sustainability.

These interconnections are exacerbated by the "fact that many of the current socio-environmental problems connected to sustainability transcend spatial, temporal, sector and disciplinary boundaries" [21] (p. 439). Governing these challenges while attempting to redesign unsustainable societies and manage a sustainability transformation in light of increasing challenges is immensely difficult. The goals to become sustainable are often mandated by high-level and often vaguely prescribed inter-/national policy and guidance to achieve these goals is often lacking, instead interpretation to meet goals falls to those responsible for land use decisions and community activities-largely local governments. So where should local governments start within participatory planning processes?

Current responses are most often compartmentalized and addressed by separate sectors, decision-making levels and disciplines. The construction of siloed knowledge cultures over time have segregated world views into individual, community, specialized, organizational and holistic modes of thinking and understanding that inhibit collaboration [22]. These 'knowledge cultures' provide varied understanding of issues that provide different version of the same reality, and use "different languages to describe the same issue, chose different avenues of action, worked to different action times and were directed towards different outcomes" [22] (p. 5). Instead, what is needed are methods that both consider and remove the obstacles and limitations of monodisciplinary and compartmentalized management to allow integrated approaches to societal problem solving for sustainability [21]. Transformation to "a sustainable society is obviously a complex endeavor, requiring, among other things, extensive coordinated collaboration across disciplines and sectors" [5] (p. 17). Overcoming sustainability challenges requires new forms of knowledge production and decision making [7] that acknowledge the overlapping nature of socio-ecological issues.

Transdisciplinary approaches can achieve this through the creation of "knowledge production for social change which is based not only on the integration of knowledge from different disciplines" and sectors [21] (p. 440). Sustainability challenges, by their nature, affect or engage a variety of stakeholders, whereby 'no single actor has the capacity or power to fully grasp or address this complexity' [23]. This understanding has led to various models of transdisciplinary, community based, interactive action and/or participatory approaches that are appropriate (and effective) models that meet the requirements posed by real world sustainability challenges [7]. This paper describes one such model and details of the case study follow.

\subsection{The Case Study}

This paper deepens previous analysis [24] of a case study revolving around a transdisciplinary scenario planning workshop involving a focused stakeholder group to explore possible alternate futures for Blekinge. Blekinge is one of 25 provinces in Sweden, it lies in the south east of the country and within its borders are five municipalities-Karlskrona, Ronneby, Karlshamn, Olofström and Sölvesborg (see Figure 1). 

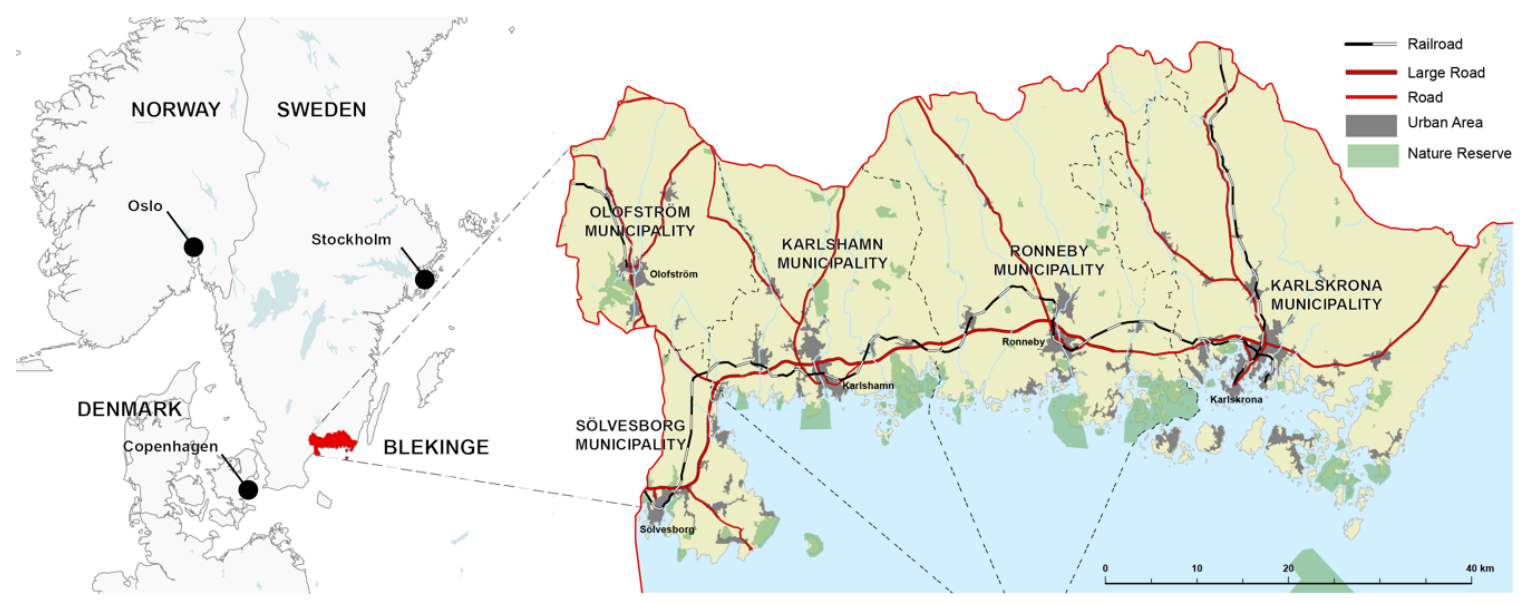

Figure 1. Map of Blekinge and its five municipalities and major urban areas (map source Länsstyrelsen/Lantmäteriet, geodata license I2018/00075).

The case study workshop was led by academics on behalf of the regional authority, Region Blekinge, to support the preparation of a regional planning process-Strukturbild Blekinge 2.0 (hereafter Strukturbild 2.0). Strukturbild 2.0 aims to increase collaboration and strengthen the link between municipal spatial planning, regional development issues by building consensus on Blekinge's most important development issues over a 30-year horizon to 2050. The scenario workshop was an important step in the process as it was hoped it would reveal shared values to support future collaborations for a regional sustainability transformation. Collectively, the stakeholders represent all communities and several interest groups in the province, as a network of networks involved in collaborative participation that is fair, representative, well-informed and transparent, in the manner called for by Innes and Booher as necessary to build trust in planning for the 21st century [25], something Sweden has a long history of doing well and that would be of interest to many other democratic societies.

Most sustainability science is grounded in the normative world view that recognizes the preservation of the biosphere as a central value [26], but in pluralist societies, such as Sweden, where values are diverse, the assumption of this central value cannot be assumed-views and definitions of sustainability are contested. Similarly, while population is increasing in Sweden, there is an urban-rural divide. In Sweden the majority of population growth can be observed in existing larger urban areas rather than in more rural regions like Blekinge. This is also true for economic growth which is also disproportionally greater in the larger population centers, a steady in-flow of talent from the hinterlands that further exacerbates rural-urban divides [27]. However, it was recognized that promoting growth for growth's sake presents uncertain consequences for regional development. Therefore, Region Blekinge determined that it would be beneficial with scenario planning with key stakeholders to explore the risks and opportunities associated with a range of alternative futures. The development and testing of such a scenario planning process is laid out in the following sections.

\subsection{Pre-Workshop Background}

Generally speaking, municipalities in Sweden have a relative planning monopoly, while the regional government is relatively underdeveloped in terms of spatial planning. It is therefore difficult for regions and municipalities to cooperate on spatial planning issues. Regions traditionally describe regional visions and outline economic development and transport strategies while the municipalities develop concrete policies and spatial plans. In Blekinge, the political will to grow in a sustainable manner was already established by the regional actors, but the responsibility for such a transformation is dispersed across several organizations including Region Blekinge, Blekinge's five municipalities, the County Administrative Board, the Swedish Transport Administration and allied organizations. 
The Strukturbild 2.0 project was developed to address such coordination shortcomings and to facilitate a collaborative strategic policy direction. Outputs of Strukturbild 2.0 include regional maps, assessments and joint strategies for development in Blekinge that public actors can use as a basis in the upcoming planning or as a basis for decision making. In 2018, prior to the engagement of the researchers in this project, the participating public actors together identified that Strukturbild 2.0 should focus upon four key regional development areas:

- Infrastructure and transport,

- Blekinge development at large,

- Labor market, business, and tourism,

- Attractive cities and living environments.

The collaborating public actors also pointed out approximate targets and measures for each of the issues. Population growth in Blekinge lags behind the national average and the potential benefits of a larger population in Blekinge, to maintain or improve the productivity of the economy and workforce, were also emphasized.

\subsection{Aim and Scope of the Workshop}

This study can be considered an action research project revolving around a participatory transdisciplinary workshop which was conducted in close cooperation with regional stakeholders, particularly planners. It is worth noting that, although many aspects of sustainability are linked to land use and are impacted by land use planning policy, rarely are planners given the space to consider the impact of their decisions upon regional or global sustainability. Planners rarely have interest or scope to consider transformative practices focusing instead on ensuring that formal planning processes and outcomes are legally correct [28]. Action research is very useful for addressing our sustainability crisis [29] and exploring transformative processes that actively seek to question the way we produce and use knowledge in learning, education and research [29,30]. It is of the pragmatic philosophy that "knowledge is assessed by its practical consequences and not only by its explanatory power" [30] (p. 5).

Bradbury et al. [30] highlight the importance of the collaborative nature of action research and its ability to enable social/organizational or community learning through a process of dialogue and scaffolding-helping learners learn together by linking experience with sense-making and reflection to action [31]. This action research project consists of two distinct strands, firstly to support Region Blekinge develop scenarios to inform future policy, and secondly to research this transdisciplinary process and better understand how to do this effectively and share those findings.

The project was initiated when Region Blekinge engaged the authors to facilitate a scenario-planning process with local, regional and national stakeholders. The idea was to develop an approach to consider alternative futures over a 30-year horizon (to 2050). Region Blekinge emphasized that the scenarios should include the four identified regional focus areas as mentioned above and relate to the overall targets and measures already pointed out by the public actors.

Initially, Region Blekinge sketched out two significantly different preliminary scenario descriptions as a starting point:

"Planning as usual" (nollalternativ) showing what happens if the region continues to work on the same path as it does today. How many houses will be built? How will the business sector develop? What types of transport will be used, etc.?

"Fully developed Blekinge" (fullt utbyggt läge) showing what Blekinge will look like when all the overarching targets have been fulfilled in the four identified key areas of Strukturbild 2.0. What will Blekinge look like in a high population growth scenario (assuming 300,000 inhabitants by 2050 from 159,000 inhabitants in 2019) with happy inhabitants that can live, work and transport themselves in a sustainable way?

The practical implementation of the workshop was divided into a few separate tasks: 
- To make at least three different scenarios for Blekinge 2050, including specified measures within the four identified key areas of Strukturbild 2.0 (described in the previous section),

- To arrange and lead a workshop in Swedish with public actors in Blekinge,

- To present the scenarios and the measures in a written report, and

- To have continuous contact and regular follow-up and involvement with Region Blekinge during the whole process.

\section{Methods}

\subsection{On Scenarios and Scenario Methodology}

A scenario is often defined as a description of a possible future [32] and a scenario may also be used to describe a pathway to a certain future. It is also important to distinguish scenarios from a likely future. Rather than a prediction, scenarios should allow for a new perspective(s) on a situation, coming to non-conventional conclusions and posing new questions [33]. Often, scenarios are used instead of or alongside visioning statements and support the development of the pathways towards desirable futures [32,34-36]. This workshop utilized an 'explorative' or 'exploratory' scenario approach $[4,37]$. Explorative scenarios aim to assess the range of future options and they usually employ two fundamental and largely independent variables in order to systematically map parallel, possible future scenarios [34]. In this case, the scenarios show four possible futures based on different development drivers over a medium term (30-year) horizon. The idea is to broaden perspectives of the future, to embrace uncertainties and inspire different actions than those foreseen in the present. In this sense, the scenarios assist decision-makers to compare possible implications of different strategic decisions and to adjust policy direction accordingly to increase the likelihood of a preferred future being realized. Region Blekinge placed a criterion on the workshop to assemble stakeholders for only one day-we refer to this as a 'rapid scenario' planning workshop. While we refer to it as 'rapid', this relates to the time input for the participating stakeholders. The organizing team still put in considerable time both for preparation prior to the one-day event and for a post-workshop theming and analysis of stakeholder input. The entire process can be considered as three phases-pre-workshop, workshop, and post-workshop, see Figure 2. The study phases are described in detail in Section 2.3.

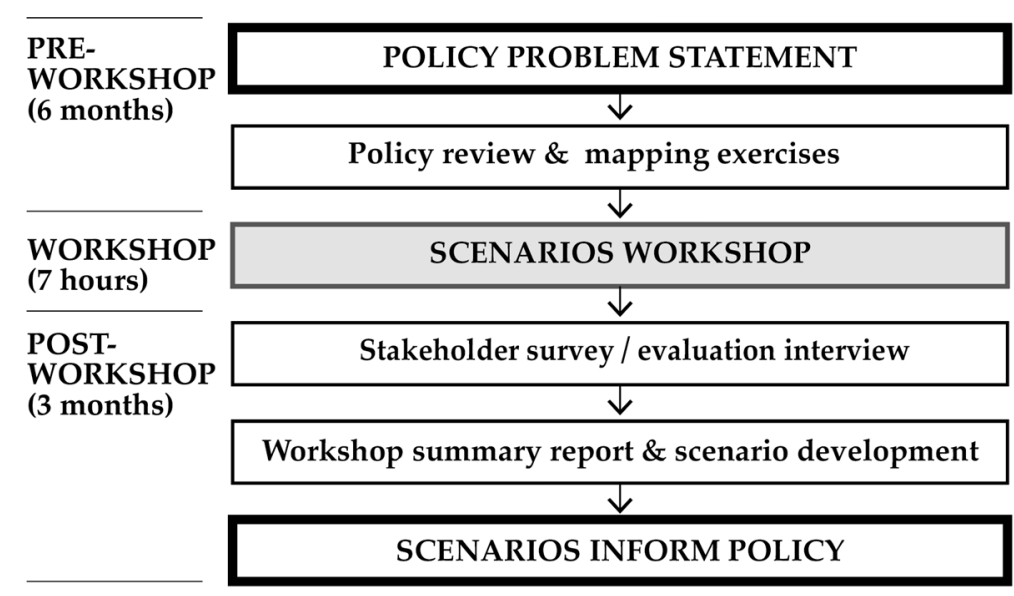

Figure 2. The three main phases of the scenario process.

Compared to a typical explorative scenario planning approach [34], the rapid scenario planning process requires more extensive preparation (in this case by the researchers) to develop scaffolding techniques that compress the workshop time requirements by allowing the participants to quickly focus on the key issues for exploration. Detailed description of the steps the research team has performed, and the scaffolding techniques used, can be found in Section 3.1. 
2.2. Using the Framework for Strategic Sustainable Development (FSSD) to Define the Sustainability Boundary

To ensure that the workshop considered sustainability beyond currently hot topics like climate change and resource efficiency, the study used the Framework for Strategic Sustainable Development -FSSD with its eight socio-ecological sustainability principles that act as a holistic boundary object to define sustainability [5]. This framework has been tested and used in both public and private sectors [38-40]. It has also been used in previous related studies involving some of the same stakeholders from Blekinge. This includes the multi-stakeholder GreenCharge project that studied how electric vehicle systems could contribute to faster transition to sustainable passenger transport [41].

Practical application of the FSSD is facilitated by an ABCD planning procedure that revolves around generic and operational sustainability principles (SPs) that provide a robust sustainability definition [42] (see Figure 3).

- Step A. Define a sustainable vision within constraints set by sustainability principles (SP1-8). This includes that:

- Nature should not be subject to systematic poisoning (meaning not allowing increased concentrations of substances from the Earth's crust (SP1) or from society (SP2)),

- Nature should not be subject to other systematic physical destruction (SP3),

- People should not be subject to systematic structural social obstacles to meet their needs (SP4-8).

- Step B. Scrutinize current situation in relation to the vision.

- $\quad$ Step C. Identify possible future solutions.

- Step D. Combine strategically prioritized solutions into roadmaps for sustainability transition/transformation that bridges the gap between the current situation and the future sustainability vision.

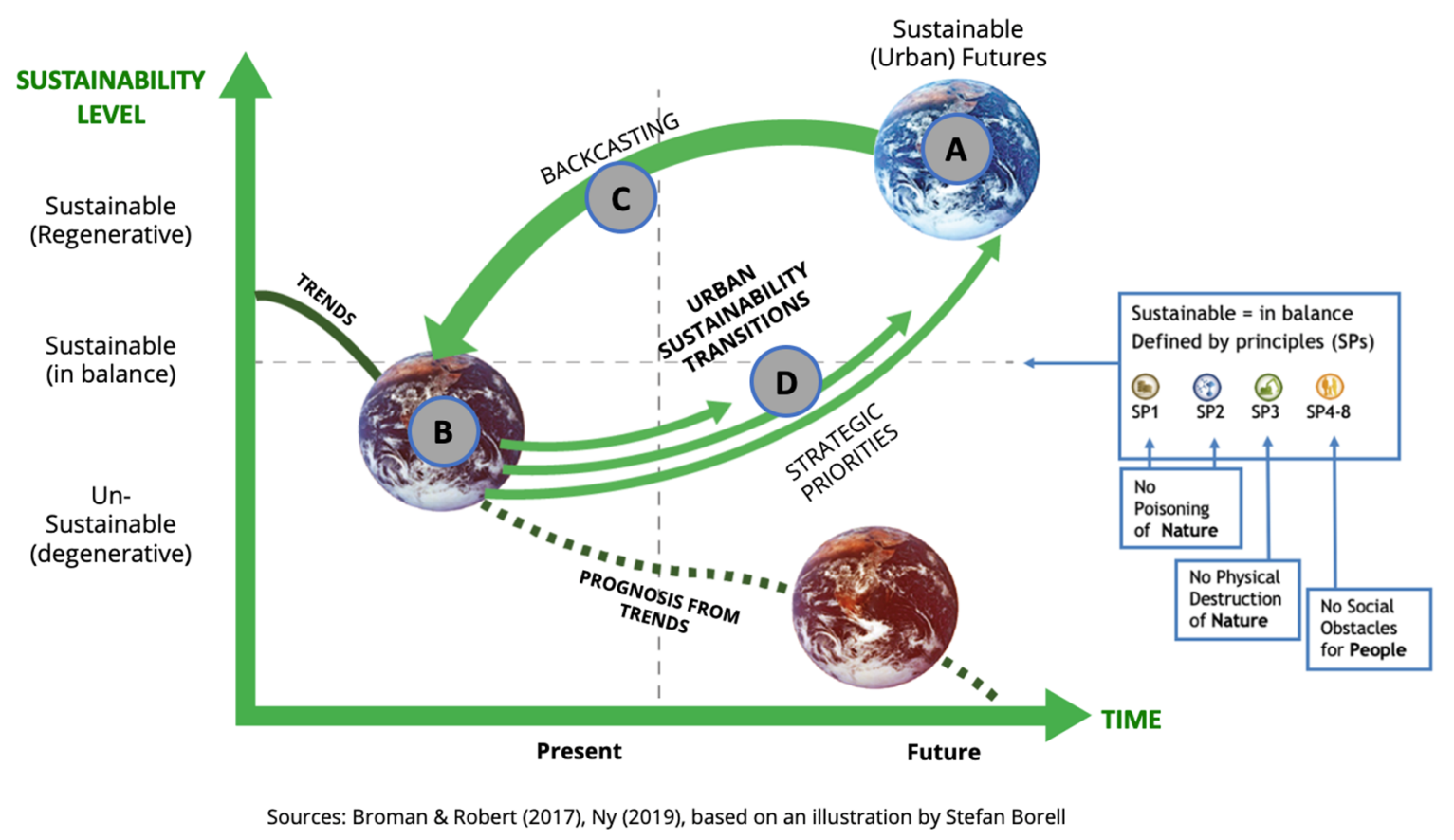

Figure 3. The ABCD process summary diagram (based on an illustration by Stefan Borell).

The scenario planning approach of this paper mainly aims to draw from and add value to step A of the $\mathrm{ABCD}$ procedure. 


\subsection{Study Phases}

An outline of the three study phases-pre-workshop, workshop and post-workshop are detailed below.

Phase 1 involved pre-workshop preparation activities by the research team with support from Region Blekinge in the six months leading up to the workshop. Activities included understanding the policy context through an existing policy review, and consideration of scaffolding approaches to aid with stakeholder understanding and to make the workshop event more efficient. Development of appropriate scaffolding approaches is the key to compressing the workshop timeframe to enable a 'rapid scenario planning' approach. The urgent and unpredictable nature of wicked problems will require agility in planning responses, input from diverse stakeholders in short time frames and quick turnarounds of plans to address the rapidly evolving global world we live in. Scaffolding approaches in this context included the identification of scenario factors and speculative spatial mapping; these are described below.

- Policy review and policy problem statement: To prepare for the workshop the research team analyzed relevant policy documents from the six main authorities responsible for the governance of Blekinge (five municipalities and Region Blekinge). In particular, the research team looked for common themes in the existing vision statements. The synthesis of these values informed the policy problem statement summarized by the question: 'How can we deliver an attractive and sustainable Blekinge in 2050?' This was the calling question for the event and shaped the workshop planning. Key themes from policies were noted and summarized into a series of prompt cards for use by facilitators on the workshop break-out tables.

- Development of scenario factors: Secondly, the researchers identified possible key external factors and drivers for Attractive and Sustainable Blekinge. The researchers used the policy review, an iterative brainstorming approach around possible key external factors and drivers that would influence an attractive and sustainable Blekinge in 2050. Following a confirmation with Region Blekinge, regional population development and sustainability performance came out as two key independent variables for the explorative scenario matrix in Figure 4 and as used in the workshop. On the population axis 'same population' means little variation from the current 159,000 residents, whereas 'larger population' means around 300,000 residents. For the sustainability axis we refer to the framework for strategic sustainable development (FSSD) as described earlier.

- Speculative spatial mapping: Blekinge is renowned for its forests, especially oak, which is the region's symbol, and also for its coastline with the Blekinge archipelago, where the 'oak forest meets the sea'. Blekinge's geographic setting is highly valued (forest, sea and archipelago) and was seen as a key component of the regional identity and an attractor. Therefore, the research team saw land use, spatial planning and access to nature as a central component of any successful future vision. Speculative mapping diagrams were also prepared to visualize the likely land-take implications of urban development due to population increase in the region. The maps were developed with the support of the County Administrative Board (Länsstyrelsen) Blekinge and their GIS mapping team. The speculative spatial mapping exercise and how they were used as a pedagogic tool to support the workshop participants is discussed in detail in the next section.

Phase 2 involved the seven-hour workshop event itself. The workshop was centered around the explorative scenarios as described in Section 2.1, using the variable axes in Figure 4. Ensuring sufficient time for participant discussion and interaction was seen by Region Blekinge and the researchers as critical. Even though also considered important, time was trimmed from presentations and introductory material to give room for more discussion time and feedback opportunities for the participants. The workshop activities are summarised in Appendix B. 


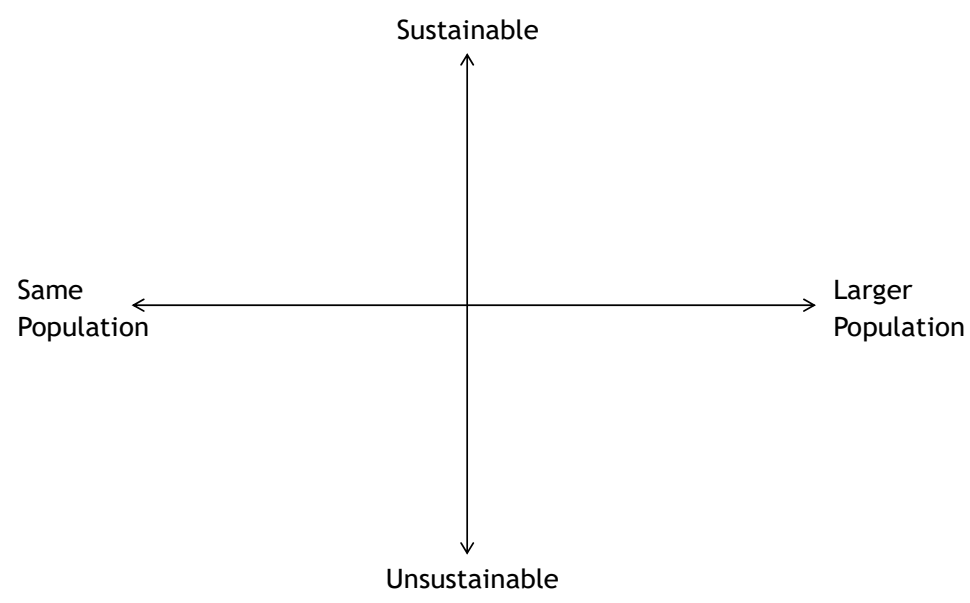

Figure 4. The explorative scenario matrix and variable axes used for the Strukturbild 2.0 workshop.

Phase 3 involved a post-workshop data collation, analysis, background report and evaluation surveys and interviews over a three-month period. Details follow:

- Background report: The material was collated by the research team and workshop responses themed into brief scenario statements (Section 3.2.2). A 24-page summary report was prepared for Region Blekinge and shared with other local actors. The report is available on the Region Blekinge website (in Swedish) [43],

- Post-workshop survey: Following the workshop, an evaluation survey consisting of eight questions to be answered, using a 5-point Likert scale to rate aspects of the workshop and one open-ended question, was emailed to the 43 participating stakeholders. The survey had a $37 \%$ response rate $(n=16)$, the results are described in the evaluation section, and

- Post-workshop interview: following the workshop, a one-hour evaluative interview with the Strukturbild 2.0 project manager was conducted using video call and recorded. Key quotes from this call are used in the evaluation section to provide some indication of the effectiveness of the rapid scenario planning approach from the perspective of the end user.

\section{Results}

\subsection{Pre-Workshop}

The time constraints on the workshop was a concern to the research team, as a longer workshop provides greater flexibility. But an advantage was that many within the stakeholder group had previously worked together and all the stakeholders were practitioners with considerable and broad existing knowledge of Blekinge. In this sense they can be described as a 'community of practice', which can be defined as "networks of people who share the same professional practice and who come together as a community to create shared knowledge to develop individual members' capabilities, and to work together" to solve shared problems [44] (p. 642). In addition, there was an agenda with practical aims-to explore what an 'attractive and sustainable Blekinge' might look like in 2050. The policy review revealed existing vision statements; the existing regional development strategy vision statement is "An Attractive Blekinge-where more people want to live, work and visit". Each authority also has its own vision, aligning visions is important to ensure that all actors in a whole region are working towards a shared outcome. A key function of this workshop was to improve co-ordination and collaboration in achieving the overarching aspirational goal of 'Attractive Blekinge'. The document synthesis of existing vision statements was conducted and found varying emphasis upon sustainability. There was some variation between the various municipality visions but there were also some strong common themes including: 'utbildning' (education), 'invånarna' (the inhabitants), 'attraktiv livsmiljö' (attractive living environment), 'näringsliv' (the business sector), 'unika läge' (unique locations) and 
'kultur' (culture). From an action research perspective, developing shared understanding in partnership with practitioners is critical as it means practical aims are more likely to be met [45]. But to support the practitioners in their goal within the short workshop timeframe the educational concept of 'scaffolding' techniques, i.e., tools that support student (or participant) learning in project-based work [46] "to develop learners' capacity for linking experience with sense making and reflection to action" [30] (p. 6). The research methodology was designed to include scaffolding, for example the scenario quadrants-to focus attention when developing the four possible future visions, and in the description of the ABCD process, as a way to operationalize the preferred vision (step A). However, research indicates that the role of spatial configurations and geography in sustainability transitions is often overlooked, and consequently there is a need to make this connection more explicit [18,47]. Therefore, the research team decided that developing supporting material to visualize land use implications resulting from population increases could also assist as a scaffolding tool, as described in the next section.

\section{Speculative Spatial Mapping to Visualize High Population Growth Development Alternatives}

In a report to the Swedish Government Region Blekinge identifies increased attractiveness for residents, visitors and businesses as the overarching growth priorities for Blekinge 2021-2027 [48]. The stated reason for working with increased attractiveness is to get more people to choose to settle in Blekinge, to establish and develop companies in the region and to come for visits. Summarized in the policy problem statement: How can we achieve an 'attractive and sustainable Blekinge?' The current status of Swedish sustainability transformation is also relevant here. One of the persistent challenges facing Sweden and outlined by the Swedish Climate Policy Council [17] is reducing transport related emissions. The report states [17] (p. 12), "With present conditions and decisions, the transport sector will only reach halfway to the target of decreasing emissions by at least $70 \%$ by 2030 . This demands powerful political actions during this mandate."

Addressing emissions reductions will have implications-particularly for the carbon intensity of vehicle fuels, vehicle use and for land-use planning [49]. Co-location of services and public transport to population concentrations can greatly assist transport emissions reduction. Residential proximity to social infrastructure and services (shops, schools, etc.) reduces the distances people must travel for daily needs and encourages walking and cycling instead of driving [50]. Similarly, clustering population and services along public transport corridors increases ridership, which creates a virtuous cycle of higher public transport frequency and increased convenience. An additional benefit of higher density development is a reduced development footprint which preserves agricultural and ecological land [50]. An added benefit to municipalities of compact urban footprints is the reduced public realm area (e.g., streets and parks) and a corresponding reduction in public authority costs associated with the 'maintenance burden' because there are more rate payers per hectare of land and less surface area to maintain. Yet current development trends in Blekinge are going in the other direction. Figure 5 gives some indication on how changing planning policies from the C20th onwards have supported increasingly lower density development in Karlskrona, this is typical for all major urban settlements in Blekinge.

Given the above-listed potential benefits, there are valid reasons for planners to consider shifting focus towards denser future city development for Blekinge. Different settlement patterns have different sustainability implications in a region, with high density development typically having less adverse effects than low density sprawl [51]. Therefore, in an attempt to illustrate the spatial effects of various potential future development paths, Figures 6 and 7 compare the current land take (urban footprint) area of the five major urban settlements in Blekinge (Figure 6), to four alternative urban footprints of different density to accommodate 300,000 residents, i.e., approximately 150,000 new inhabitants or about 68,000 new dwellings (Figure 7). Calculation details and assumptions are given in Table 1. 


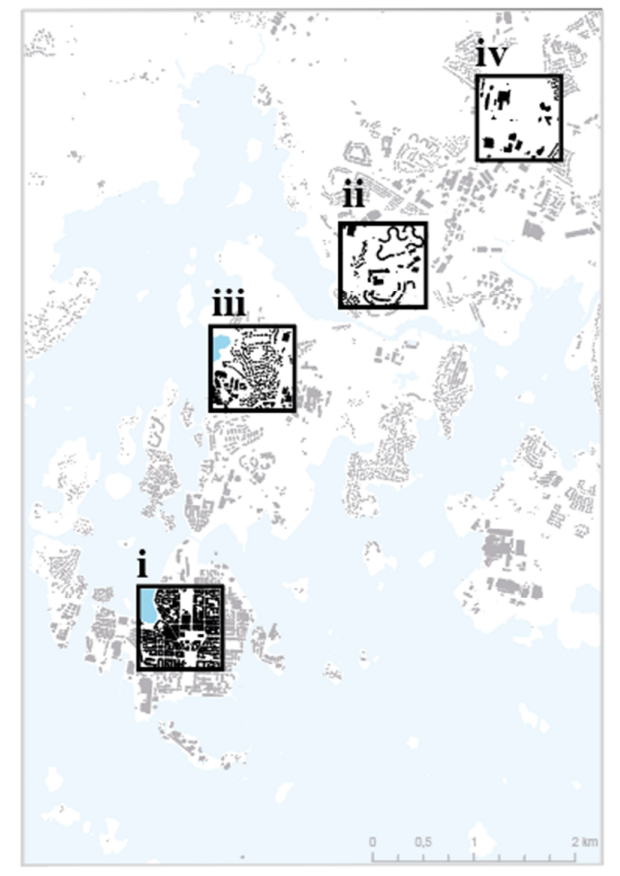

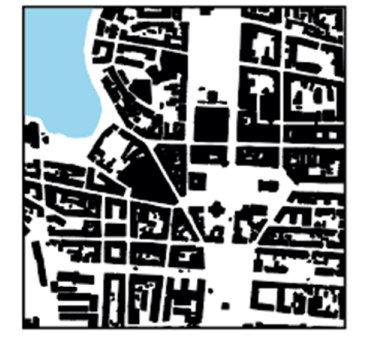

i Trossö, dense Baroque urban plan c. 1680 . Approx. density $200+$ dw/ha

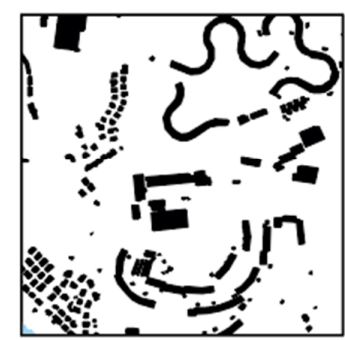

ii Kungsmarken. c. 1960s Approx. density $50 \mathrm{dw} / \mathrm{ha}$

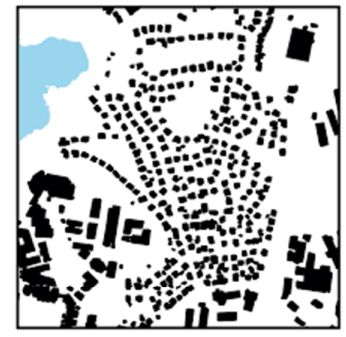

iii Bergåsa transit adjacent 'garden city' suburb c. 1900-50 Approx. density $20+\mathrm{dw} / \mathrm{ha}$

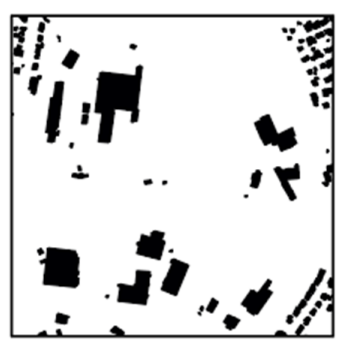

iv Lyckeby 'car dependent' development c. 1980 s - 2000s Approx. density $<10 \mathrm{dw} / \mathrm{ha}$

Figure 5. Figure ground showing the urban spatial pattern evolution over four time periods in Karlskrona: from 1680 (i), to 1900s-1960s (ii and iii) and to 1980s-2000s (iv). Urban development in the latter half of the 20th century is increasingly dominated by inefficient low density car-oriented sprawl (map data source: Länsstyrelsen/Lantmäteriet, geodata license I2018/00075).

\section{Sölvesborg}
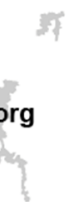

Olofstrom
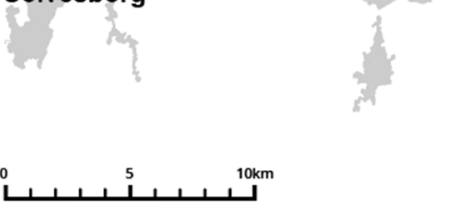
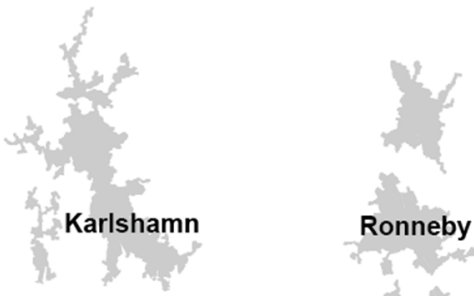

Figure 6. Comparative urban footprints for the five major settlements in Blekinge (2019). All are at the same scale for the correct geographic position of the towns, see Figure 1.

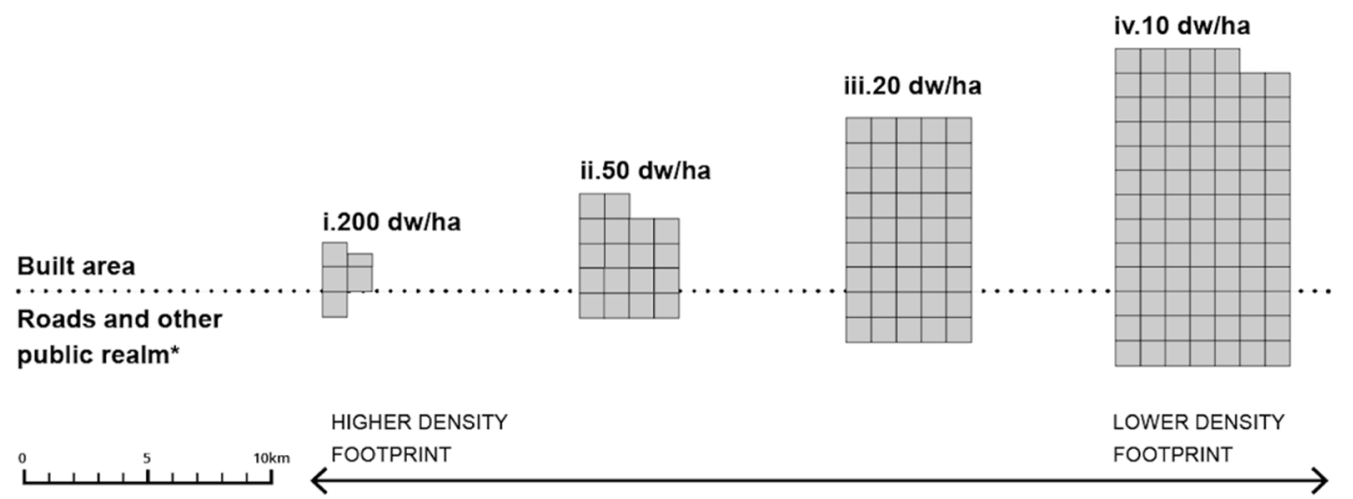

Figure 7. Representation of the 'Total minimum footprint' alternatives for 150,000 new residents (approx. 68,000 dwellings), see Table 1 (same scale as Figure 6). 
Table 1. Additional land (footprint) needed for 150,000 new residents (approx. 68,000 dwellings) at four alternative future population densities (i-iv).

\begin{tabular}{|c|c|c|c|c|c|c|}
\hline $\begin{array}{l}\text { Future Alternative } \\
\text { (Figure 7) }\end{array}$ & $\begin{array}{l}\text { Added Population } \\
\text { (People) }\end{array}$ & $\begin{array}{c}\text { New } \\
\text { Dwellings * }\end{array}$ & $\begin{array}{l}\text { Population Density } \\
\text { (dw/ha) }\end{array}$ & $\begin{array}{l}\text { Development } \\
\text { Footprint }\left(\mathbf{k m}^{2}\right)\end{array}$ & $\begin{array}{c}\text { Public Realm } \\
\text { Footprint }{ }^{* *}\left(\mathrm{~km}^{2}\right)\end{array}$ & $\begin{array}{l}\text { Total Min. Footprint } \\
\qquad\left(\mathrm{km}^{2}\right)\end{array}$ \\
\hline $\mathrm{i}$ & 150,000 & 68,182 & 200 & 3.4 & 1 & 4.4 \\
\hline ii & 150,000 & 68,182 & 50 & 13.6 & 4.1 & 17.7 \\
\hline iv & 150,000 & 68,182 & 10 & 68.2 & 20.4 & 88.6 \\
\hline
\end{tabular}

* Assuming 2.2 people/dwelling, ${ }^{* *}$ Public realm footprint includes roads and open space, it is assumed at $30 \%$ of development footprint (min.)

The urban footprints in Figures 6 and 7 are all drawn to the same comparative scale. The future alternatives range from high density of around 200 dwellings per hectare (dw/ha) (the type of density commonly found on central Trossö) to low density sprawl of approximately $10 \mathrm{dw} / \mathrm{ha}$ (typical of new suburban development in Blekinge). Implications from the alternative spatial planning policies include the following:

- Lower density allows more villas which are currently perceived as more attractive for residents,

- Lower density development displaces agricultural and ecological land,

- Higher densities provide greater proximity benefits bringing people closer to services or amenities (e.g., shops, schools, health, public transport, forest, sea etc.),

- Higher densities allow more cost-effective services such as public transport, maintenance budgets (due to both higher land tax density and less public realm), district heating, and so on.

These urban footprint comparisons give an indication of how land use decisions might impact the region's sustainability performance. The next section describes general planning considerations for sustainability.

\subsection{The Workshop}

Starting from actors involved with the project Strukturbild 2.0, a list of key stakeholders was identified. The workshop took place on 11 June 2019 at Militärhemmet in Karlskrona (see Figure 8). The workshop was attended by a total of 43 participants representing 13 organizations in Blekinge and two outside of Blekinge (an external facilitator and a researcher) (See Table A1, Appendix A). There were representatives of all municipalities and several organizations that work across the region, representing strategic societal development and spatial planning in the public sector.

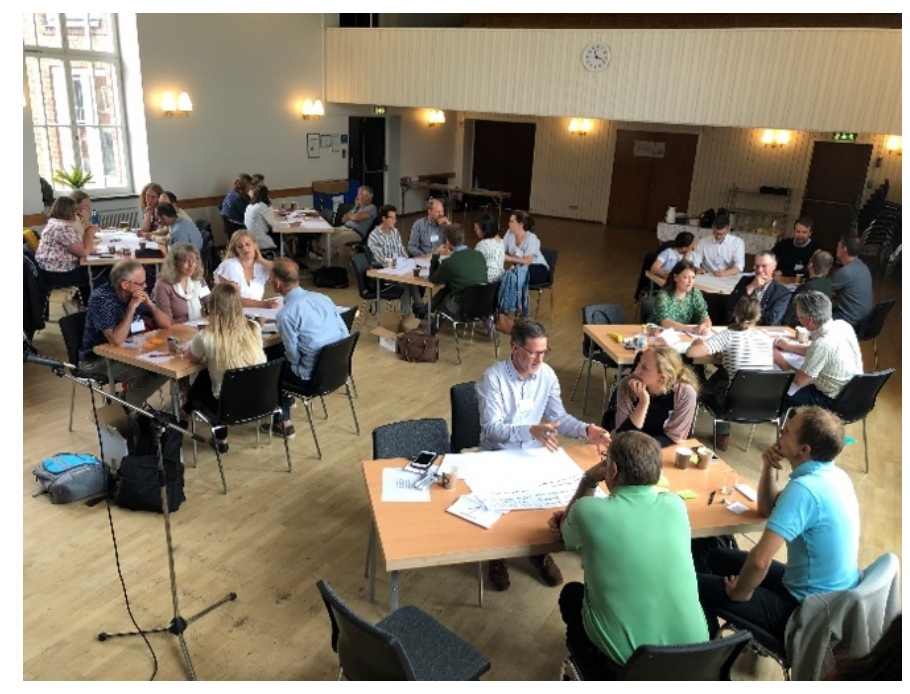

Figure 8. The Stakeholder Workshop (picture by G. Thomson). 
In the workshop, the stakeholders worked in smaller groups to first identify what attractive and sustainable Blekinge meant to them today and then to give their input on how they envision the four potential futures of the scenario matrix and what might need to happen or not happen for them to become reality. The researchers then synthesized the workshop results into four scenario narratives.

The picture of what makes Blekinge attractive and sustainable to live in, run businesses and visit has been sketched out in the regional development strategy (Region Blekinge, 2018) and this includes:

- Proximity to European growth markets, good communications and commuting opportunities;

- A unique coastal landscape and archipelago offers great recreation opportunities;

- A good innovation climate and closeness between people creates collaboration opportunities.

The public stakeholders in the workshop also listed the factors they thought might contribute to or hinder an attractive and sustainable Blekinge in 2050 (see Table 2).

Table 2. Contributing and hindering factors for an attractive and sustainable Blekinge in 2050 according to key public stakeholders.

\begin{tabular}{|c|c|}
\hline Contributing Factors & Hindering Factors \\
\hline History and World heritage empowers the brand & Aging population $\geq$ less tax revenue \\
\hline Geographic contact with international trade & In the corner of Sweden = far away from large cities \\
\hline $\begin{array}{c}\text { Close to nature (e.g., farming and forestry, hiking paths, } \\
\text { archipelago, tourism) }\end{array}$ & $\begin{array}{l}\text { Restrictive beach access, world heritage nature/cultural } \\
\text { values and sea level rise limits new residential areas. }\end{array}$ \\
\hline Close to everything_-a small county & Limited cultural offers \\
\hline $\begin{array}{l}\text { In general, cheap housing and attractive (natural) locations } \\
\text { compared to large cities }\end{array}$ & $\begin{array}{l}\text { A relative lack of cheap housing in the cities (e.g., for } \\
\text { students) due to urbanization }\end{array}$ \\
\hline $\begin{array}{l}\text { Generally good infrastructure (e.g., railroads, highways, } \\
\text { ports, and an airport) }\end{array}$ & $\begin{array}{l}\text { Relatively worse communications and infrastructure outside } \\
\text { the cities }\end{array}$ \\
\hline \multicolumn{2}{|l|}{ Linear coastal cities enable good public transport } \\
\hline \multicolumn{2}{|l|}{ New efforts for public transport by sea } \\
\hline Large world-class employers & Dependency on a few large employers, small job market \\
\hline $\begin{array}{c}\text { Blekinge Institute of Technology (BTH) and Science Parks } \\
\text { and their expertise }\end{array}$ & $\begin{array}{l}\text { BTH research focus on technology limits growth in other } \\
\text { subject areas }\end{array}$ \\
\hline Competence development instead of recruitment & Niched education does not always meet local needs \\
\hline Security through navy- and air force bases & Military training causes noise, emissions \\
\hline New influences and ideas & Weak small business spirit \\
\hline Growing Blekinge spirit and pride & $\begin{array}{l}\text { Local patriotism and conservatism counteract community } \\
\text { collaboration and can be resistant to change }\end{array}$ \\
\hline Support for a regional rather than a local perspective & Difficult to develop the countryside \\
\hline Transformation towards sustainability together & In general, a low level of competence in sustainability \\
\hline \multirow[t]{2}{*}{ Big potential for local renewable energy } & Opposition from the defense hinders new wind power \\
\hline & $\begin{array}{l}\text { Non-equal society with alienation among elderly, loners and } \\
\text { recent arrivals }\end{array}$ \\
\hline
\end{tabular}

\subsubsection{Scenario Descriptions and Drivers behind Them}

This section starts with a summary of the scenario descriptions gathered from the workshop (see Figure 9) and then follows a series of further developed scenario narratives and likely drivers behind them that the research team developed (see Section 3.2.2). 


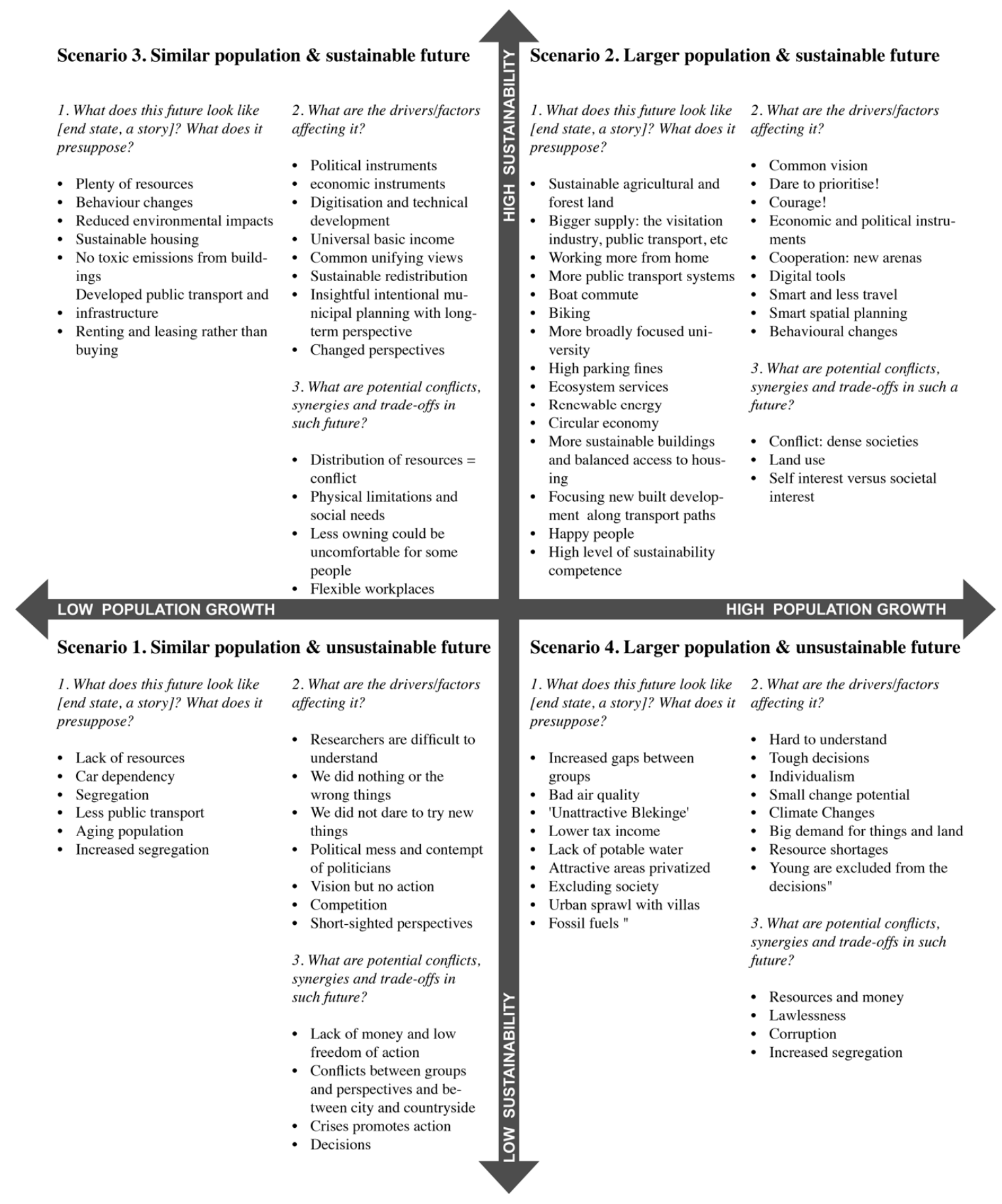

Figure 9. Summary of the input on the four scenarios from the Scenario Workshop (translated from Swedish).

\subsubsection{The Four Scenarios}

The following sections describes the four scenarios resulting from the workshop (translated from Swedish).

\section{Scenario 1: 'Business as Usual' with Similar Population and Low Sustainability}

In this potential future, 'business as usual' has prevailed. The region has become known as quaint with its 'old fashioned' ways while its reputation as a desirable region to live in has suffered. Regional 
problems such as car dependency, segregation and the aging demographic remain. The population has also stagnated regionally despite increasing in most parts of Sweden. As a consequence, societal economy has also deteriorated. People have lost respect in politicians and the general level of conflict is high in the region.

The main drivers behind this future include poor communication between science and society with a lack of evidence-based political leadership and long-term sustainable policy direction. This shortcoming would be compounded if there was an insufficiently strategic systems approach to formal decision making processes to manage sustainability work across disciplines and societal sectors. Parallel ongoing work at the Blekinge Institute of Technology has identified these shortcomings as a barrier to municipal and regional sustainability progress at the moment (see upcoming licentiate thesis by Lisa Wälitalo in 2020). National and international goals (e.g., Paris Agreement, SDGs) were also low on the agenda. This meant a lack of investment resulting in unsustainable environmental, social and economic outcomes across the region and reduced capacity to address these areas as they worsened.

In this future, the main conflicts are between city and countryside and between the politicians and sections of society seeking more action on economic, social and environmental problem areas.

\section{Scenario 2: 'Blind Growth' with Larger Population and Low Sustainability}

In this potential future, a high and unlimited 'blind growth' has been assumed, based on the notion that 'bigger is better' regardless of what it is that grows. Houses are relatively cheap compared to other parts of Sweden and most new residents have moved to villas with large gardens on the edge of existing urban areas. Population growth has brought new life to the economy and a larger tax base. People are better off economically but social isolation and chronic disease such as obesity has grown as people spend more time in cars and must travel further to access recreation facilities and forests. In the coastal cities, few people get to live by the water as most development land is to the north. Public transport also struggles to effectively service a dispersed population and traffic congestion is more common. The environment has suffered with loss of local amenity (e.g., forest cover) but also with considerably increased greenhouse gas emissions.

\section{Scenario 3: 'Greener Blekinge' with Similar Population and High Sustainability}

In this potential future, a 'Greener Blekinge' has a stabilized population and considerably improved sustainability performance at the local level. Considerable advances have been made for achieving the national and international sustainability goals through reductions of emissions, reduced waste, water and energy demand per capita while quality of life has remained high. EV car share schemes are common for longer trips to areas not serviced by public transport. As a consequence, societal economy has improved moderately.

The main driver behind this future was that the region developed a strong shared vision and found it relatively easy to implement because it did not also need to accommodate many new residents. A contributing factor behind this was probably that the region more systematically used a strategic systems approach to manage sustainability work and established a formalized meeting culture across disciplines and societal sectors. Priority was given to measures that increased efficiency and community capacity to reduce long-term running costs. Local ecological areas and farmland near the major urban centers were preserved to maintain access to the picturesque areas within short distances of most residents. Building stock was rebuilt or retrofit to be highly sustainable. Public transport, walking and cycling initiatives reduced reliance upon private cars. A strong emphasis on collective action and the introduction of a universal basic income led to a comfortable and socially supportive environment. Historic buildings and heritage structures were celebrated and preserved to help build the Blekinge brand as a quiet, sustainable and beautiful place to be in.

In this future, the main conflicts happen around some residents who find collectivist ideals, collaborative consumption and new general flexibility challenging. Still, the changes have benefitted most people. 
Scenario 4: 'Restart Blekinge' with Larger Population and High Sustainability

In this potential future, called 'Restart Blekinge', the region is reborn with a high population and new flourishing emerging sectors such as green technology, ICT, marine environments, education and tourism. Blekinge has a reputation as a leading region for sustainability and innovation for 21st century societal transformation. A place where the creative classes can find good work opportunities while also finding a great living environment within dynamic urban centers that have excellent access to nature. Digital tools monitor and optimize performance and great advancement has been made towards fulfilling (inter)national goals. With most residents, employment areas and services close to high frequency public transport, fewer cars are needed. As a consequence, very little forest or agricultural land is needed for new development and the societal economy has improved considerably.

The main driver behind this future is courageous leadership towards innovative green entrepreneurship. As in scenario 3, a probable contributing factor behind this was that the region used a strategic systems approach to manage sustainability work and established a formalized meeting culture across disciplines and societal sectors. Strong regional policies have also attracted investment and population and this has, in turn, been channeled into further improvements in a virtuous cycle. Planning policy clustered land uses to improve walking, biking and boating options, while also integrating public transport viability and frequency. Historic buildings and heritage structures were celebrated and preserved to help build the Blekinge brand as a future-oriented center for sustainable innovation that also celebrates its cultural heritage. Balancing both opportunity and lifestyle, Blekinge is the place people want to move to.

In this future, the main conflicts are around land use and lifestyle as some people miss the small-town 'vibe' that has been replaced with more of a city 'vibe' in the new denser areas. Still, the focus on 'growing within the existing urban footprint' means that most people have high quality natural areas nearby.

\subsection{Post-Workshop}

\subsubsection{Post-Workshop Stakeholder Survey}

A survey was emailed to all participants after the workshop. The survey questions and results (Likert 5-point scale) are summarized in Table 3.

Table 3. Post-workshop stakeholder survey summary results.

\begin{tabular}{llc}
\hline & \multicolumn{1}{c}{ Survey Question } & Average Score out of 5 (Range) * \\
\hline SQ1 & Overall impression of design and content & $3.0(1-4)$ \\
SQ 2 & Overall impression of moderator and speakers & $3.4(2-4)$ \\
SQ 3 & Overall impression of the venue, lunch and fika & $3.1(2-4)$ \\
SQ 4 & Overall impression of the workshop & $3.2(2-4)$ \\
SQ 5 & Workshop design of the different phases & $3.0(2-4)$ \\
SQ 6 & Workshop design: participants' possibilities to contribute & $3.8(3-4)$ \\
SQ 7 & Workshop design: organization & $3.5(2-4)$ \\
SQ 8 & Workshop design: results $\quad{ }^{*} \mathrm{n}=16(37 \%)$.
\end{tabular}

Our interpretation of the survey was that respondents thought that the workshop was positive overall. However, as might be expected from the diverse range of disciplinary backgrounds, there was considerable variation with some responses being more negative than others. Generally speaking, responses to questions 1,2 and 5 were most relevant to the performance of the research team and facilitators on the day, lower scores for question 1 and 5 indicate that the overall design, different phases, and content could be improved. However, the impression of moderators and speakers was broadly positive. Encouragingly, it was SQ6, the highest score relating to the participants' possibilities to contribute, that received the highest score, even amongst respondents with a more negative view 
of the workshop as a whole. In terms of capacity building within a transdisciplinary collaboration, the perception of participants about their ability to contribute is a very positive result, which combined with the high degree of transparency of the process is likely to increase the acceptance and ownership of the final scenarios [37]. Specific comments were provided by some of the respondents in response to the open question what was 'most interesting to discuss during the workshop'. A summary of key findings includes the following:

- There seemed to be general interest in the creation of scenarios with interest in 'the scenarios for sustainability and population growth', particularly the 'positive scenarios' and 'positive topics'; the views of others were important-'interesting to hear how others are reasoning', and the role of individual organizations-'my organization's role in the solution',

- Broad systems thinking was alluded to in terms of interest in upstream factors i.e., 'how one can look at what can cause sustainable development',

- There was interest in ecological sustainability, but two respondents highlighted a desire for more on 'social sustainability' and 'social and economic sustainability in Blekinge'.

- Given that urban planners were participating, it is not surprising that the role of land use and planning at the local level was seen as an important topic, e.g., 'Local sustainable solutions for Blekinge', 'spatial planning and sustainability', 'residential and transport issues ... (and) where population growth can occur mainly outside the three major metropolitan areas in Sweden',

- However, there was some dissatisfaction with the level of resolution, with some wanting 'concrete proposals' and '... real results', or interested in 'What will happen to make a certain scenario to happen', or asking 'What is needed for the important but maybe less popular decisions to be taken?'

- Some respondents clearly felt the process was incomplete, with interest in scenarios: "scenarios ... show opportunity, and it is important, despite being the first step. The second step is to gather these actors and talk about their purpose/goals and how related work can be gathered. What synergy there is, etc.... I think it is not finished. Looking forward to the report and even more to the next steps."

Future survey questions would benefit from understanding the participants' disciplinary backgrounds and how comfortable they were with the exploratory scenario process. It would be interesting to see if there were disciplinary differences. Furthermore, an open-ended question about what might be improved would offer useful insights about areas to refine for future workshops.

\subsubsection{Post-Workshop Evaluation Interview}

Following the workshop, an evaluation interview was held with the project manager from Region Blekinge, from whom direct quotations are included in this summary. When asked how useful the scenarios and subsequent summary report were, the project manager mentioned that "scenarios were not initially planned" but were seen as an opportunity in the Strukturbild 2.0 process "because demands came from the municipalities that the region should also be able to work with scenarios ... The Regional Growth Agency (Tillväxtverket, who fund Strukturbild 2.0) accepted this and they seem satisfied with the result". The Growth Agency have requested that they receive and disseminate the scientific publications based on the workshop work.

The scenarios developed in the workshop have been used in subsequent meetings and workshops centered around future directions for Blekinge. "In the regional development strategy we have worked with the ABCD methodology... the scenarios in particular have helped the region to define their desired future destination" (i.e., the 'A-step' of the FSSD—a desirable vision that adheres to the sustainability principles). Region Blekinge are working with the high growth sustainable scenario 'Restart Blekinge' as the preferred future, and also exploring the low growth sustainable 'Greener Blekinge' scenario. "It was important for us to be able to link population development to sustainability." 
Regarding useful results from a one-day event, the workshop process was seen "to quickly insert large blended target groups into the scenario context", but it was most useful for the initial stage of the $\mathrm{ABCD}$ process of the FSSD (A-step) "where several actors want to find out together which way they want to go." Subsequently, over a longer period, a more concrete sustainable transformation roadmap could be developed using the $\mathrm{ABCD}$ procedure, backcasting from the preferred future and prioritizing appropriate actions.

The scenario approach was seen as a useful tool to "get more from different players' 'skills'. Given that Strukturbild 2.0 is an interdisciplinary project with diverse participants, the 'scenario four-fielder can be a good tool for framing ... (considerations for) ... future visions." The scenario approach was easy to grasp and aided participants in the envisioning exercise.

When asked how this scenario planning process could be improved, the recommendation was to ensure greater coverage of "social sustainability" as "at some tables, the focus was on environmental sustainability". It was also suggested that "future scenario workshops take some table leaders from the client organization, but it was good that BTH (Blekinge Institute of Technology researchers) had a meeting with the table leader before and that there was a structure to relate to."

Finally, it was seen as important that the scenario process was informative to a real planning process - "The scenario methodology should be linked to a concrete strategy or planning process or action selection study for best results."

\section{Discussion}

The combined evaluation (survey, interview and researcher reflection) suggests that a rapid scenario planning process is possible, but the experience of the research team indicates that considerable planning is necessary to create the conditions to enable this. Many hours of preparation fed into the workshop, and even so, the participant survey indicates considerable variation in stakeholder experience of the day.

One observation that is consistent with findings from other studies is that authorship matters, and focus will change depending upon who leads and designs the process [23], as different actors have different priorities, and this is equally true for the participants. The research team attributes some of the considerable variation in participant feedback scores to the diverse group. Some participants were clearly more comfortable with the creative scenario planning exercise than others, and the influence of participant receptivity to the scenario process deserves further study.

The importance of who should design the workshop was a consideration of the research team from the outset. As mentioned previously, the case study offered in this paper was instigated by a regulatory authority-Region Blekinge, but the workshop process was designed independently by a university research team (the authors). The authors intentionally designed the process to separate the various actors' roles.

The different role of each actor is summarized visually in Figure 10, where the activity and priority of each actor is shown in separate columns:

- Region Blekinge ensured that the scenario process had agency. Without agency, a scenario process is little more than an exercise in collective dreaming. Potential for impact was important to the researchers as previous transdisciplinary studies [52,53] describe how the perceived burden of collaboration, unclear added value and negligible real-world impact detract from the stakeholder experience,

- The BTH researchers gave the process independence from local politics and freed the exercise from the shackles of existing policies or other preconceived limitations. Governing is a deeply political process, but administrative bureaucrats have considerable agency that also enables them to affect change [31]. Hence, engaging policy makers in a long horizon scenario planning process enables them to think beyond politics overcoming the problem of connecting transformation narratives to policy process [54], and 
- Finally, the central actors of the workshop process, the stakeholder participants. This 'community of practice' collectively forms a vast repository of local institutional and community knowledge. The workshop design emphasized strategic activities, that is, formation of alternative long-term scenarios $[5,55]$. An exploratory scenarios process allowed the workshop to proceed without participants becoming stuck on technical details. Once the preferred scenarios have been selected (post-workshop), the challenge for the stakeholders will be to own the vision and collectively design the policies, strategies and tools that can move them toward that shared vision. Ultimately, this ownership will determine the overall impact of the process.

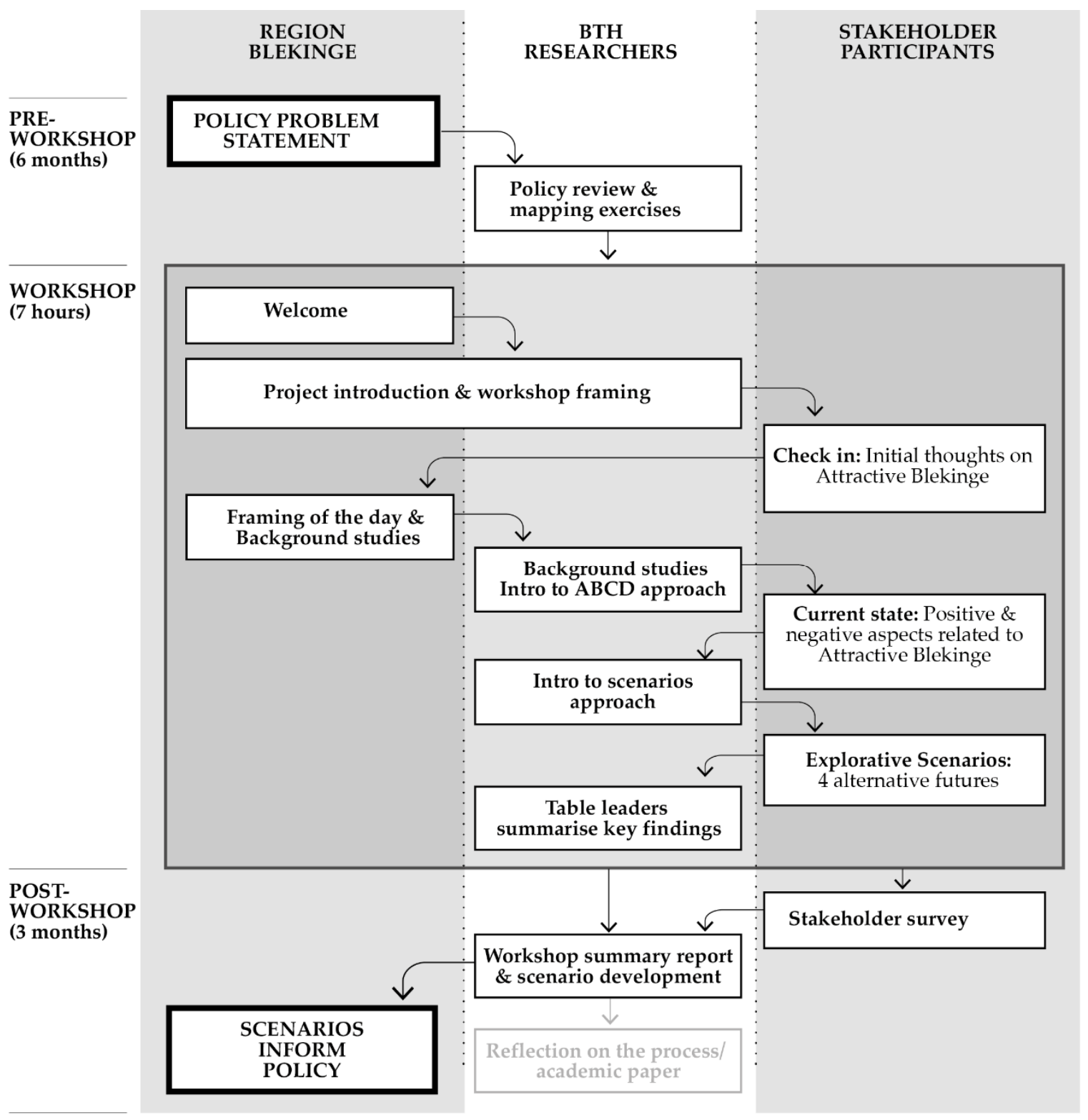

Figure 10. Summary diagram of the research phases and actor roles in the scenario process.

The time spent in the pre-workshop phase developing scaffolding approaches was seen as critical to the success of the workshop in achieving its objectives in the short time period. The scaffolding approaches used included:

- Arriving with a predetermined scenarios quadrant with its two independent variable axes (sustainability and population). In traditional scenario workshops that run over several days, 
determining the axes may be part of the stakeholders' shared deliberation. But in this case, pre-testing and confirming the axes saved considerable workshop time,

- Introducing the ABCD process from the FSSD methodology as a way to operationalize a preferred scenario (A-Step i.e., vision),

- Introducing a summary of relevant background studies and preparing prompt cards for use by facilitators to keep the participants focused upon the key issues relevant to the scenario formation, and

- Preparation of speculative spatial mapping to show potential impacts of different development patterns resulting from a high population growth, to allow participants to reflect upon the spatial implications of business-as-usual development, particularly the impact of high population growth and typical unbridled low-density urban expansion upon the highly valued geographic (forest, sea and archipelago) that form the current attractive identity of Blekinge.

Of the scaffolding techniques, the scenario axes seemed to be the most comprehensively understood, but comments from the post-workshop survey suggest the connection between the scenario exercise and an ongoing dialogue between all stakeholders to translate scenarios into policy was not so well understood by all workshop participants. Particularly the request for more concrete outcomes; this was after all intended primarily to synthesize stakeholder views around desirable futures for the region and how a preferred future could inform policy direction. It was an exercise in knowledge exchange, between the administrative 'silos' of public sector divisions and adjoining or overlapping governance bodies to inform a shared visioning process. Greater explanation of this bigger picture may have helped participants contextualize the day better, but equally more input could risk information overload. In a time-constrained workshop there will always be trade-offs about what information to include and exclude. However, given the bigger picture of translating scenarios into visions and using visions to inform policy, it was clear to the coordinating organization (Region Blekinge) that this gap in understanding may be rectified in subsequent stages of policy co-ordination.

In addition to facilitating the creation of scenarios to inform policy, the research team found the evaluation process to assess the efficacy of the project (through surveys and post-evaluation interviews) and their own subsequent reflection to be a valuable exercise in learning and process refinement. Through this evaluation process, the initial concern relating to the short workshop timespan was somewhat allayed, but success was dependent upon a good working relationship with the coordinating organization (Region Blekinge), the right scaffolding tools, and a knowledgeable stakeholder group. The scaffolding techniques presented in this case study were designed as a pedagogic tool to focus participants upon the key issues for exploration. They were instrumental to reducing overall time commitment from the participants, and the resulting compressed time frame (i.e., a one-day workshop) enabled good attendance levels. The project manager warned that a longer multi-day event was unlikely to attract a good turnout. Keeping the workshop length relatively short was seen as critical for success as this ensured good attendance, including senior managers. Attendees were also curated to maximize diversity, in terms of both sectoral interests and disciplinary backgrounds, to enhance the learning opportunities through exposure to new perspectives amongst participants. The use of an academic research team provided a neutrality in the process that may not have existed if the process was 'owned' by one of the several organizations that were participating.

The facilitated scenario process effectively became a collective exercise in sustainability foresight, working towards consensus on a future sustainability vision(s) for the region, in both high growth and low growth alternatives. This allowed a shared understanding by finding common ground for future action between a range of related organizations (1). The emphasis was on maximizing the output from the workshop through minimal time input from participants-'rapid' relates to the workshop length - but there is a transfer of time burden to the pre-workshop phase undertaken by the workshop development team. Extensive upfront preparation saves time for participants in the workshop. There is a risk, of course, that the pre-workshop preparation limits exploration; to minimize this risk the scaffolding techniques used in this case study were appropriate to Region Blekinge's specific context. 
This case study represents a small intervention in the grand scheme of a regional policy planning process. However, it does represent a relatively powerful leverage point in a larger transformation journey, by showing how a time-efficient rapid scenario planning approach can be useful to shape a shared vision, thus providing strategic direction to help align future collaboration between a range of organizations that are collectively responsible for developing sustainability transformation policy. At the outset of this case study, the research team were concerned that a one-day workshop may be insufficient to achieve a meaningful outcome capable of influencing the regional policy direction. However, despite the relatively small investment of time by participants at the workshop, the post evaluation interview with the project manager suggests that in this case even a rapid scenario planning workshop can have a considerable lasting impact-the evaluation indicated that it was perceived as reasonably successful by participants and Region Blekinge. Region Blekinge have since used the scenarios to inform further stakeholder discussions and inform strategic policy direction.

\section{Conclusions}

Transformation requires collaboration. Rarely, if ever, is one organization tasked with, or even capable of, guiding a transformation process in isolation. Rather, multiple actors drawn from many societal sectors are required, and they must work together. To be strategic, collaborative processes benefit from an alignment of direction across and between organizations. A transdisciplinary scenario process can facilitate this by allowing disparate actors to learn from one another through a dialogic process. In the rapid scenario planning approach, we describe how this can be done in a compressed time period (e.g., a one-day workshop).

Critical to the success of a rapid scenario planning process is the considerable preparation in a pre-workshop phase to develop various scaffolding approaches, e.g., in this case:

- pre-established variable axes for the scenarios (i.e., sustainability, population),

- explaining the FSSD to participants as a common definition of sustainability,

- preparation of a list of key issues to focus workshop discussions, and

- $\quad$ speculative mapping to indicate possible spatial impacts of various growth options.

In more conventional exploratory scenario planning approaches, the identification of the scenario variables (i.e., the axes), mapping exercises and other exploratory exercises would be prepared by the stakeholders themselves, thus allowing participating experts and other stakeholders much deeper engagement with the scenario content. This greater engagement requires more time, with conventional scenario processes typically held over multiple days. The evaluation of this case study shows that there is still value in conducting a 'rapid' scenario planning process that involves multiple stakeholders in a collaborative process in a shorter time frame.

This paper began by describing the importance of transdisciplinary approaches to ensure more holistic (sustainability policy) outcomes. Scenarios are a transdisciplinary tool that can reduce risks and maximize opportunities associated with alternative development paths [2], but perhaps even more powerful than this is the reflexive process scenarios require-the individual and organizational learning that results from dialogue and debate between participants. The results from this scenario case study support existing literature, in that participants were observed to:

- share knowledge and reflect upon the limits of their own disciplinary or organizational silo [30],

- learn from each other through a dialogic process to consider impacts at a broader systems level $[55,56]$,

- think over a long-term horizon (to 2050) and creatively reflect on the needs of the future [57], and

- link abstract global issues such as climate change and sustainability to local place-based values and needs.

A major recommendation to those seeking to conduct a similar rapid scenario planning process to inform sustainability transformation policy would be the importance of well-considered scaffolding 
techniques. The scaffolding techniques in this case study should certainly not be treated as an exhaustive list, nor are they necessarily transferable. Scaffolding techniques should be context-dependent and tailored to best support participants to focus upon the key issues for scenario development.

This hints at a future research direction - a systematic exploration of scaffolding approach typologies to support scenario planning processes. A typological study of approaches would complement existing studies that describe typologies related to scenario planning [4]. Scaffolding approach typologies would assist workshop designers in instances where time constraints might otherwise preclude scenario planning as a tool, and 'rapid' approaches would be beneficial. This is particularly true for smaller organizations (e.g., small regional governments) that are rarely as well-resourced as larger organizations and time away from core work has a greater negative impact upon the organization.

Ultimately, this case study used scenario planning to insert a reflexive exercise into a traditional planning process, thus allowing the participants to envision possible alternative futures, rather than just adhering to narrow path-dependent policies that also limit change by creating structural barriers to sustainability transformation. The evaluation demonstrated that even a rapid scenario planning process can engage participants in a collaborative learning exercise; in this instance, one that improved the collective understanding of a community of practice to help align stakeholder interests as they embark upon a regional sustainability transformation.

This paper was limited to one case study, but we expect some of the approaches to be generalizable to similar contexts, although this is beyond the paper's scope. However, we imagine that similar rapid scenario planning processes could be useful for planners and policy makers to explore other complex issues where there is great uncertainty, limited participant time resources, and where the topic would benefit from broader transdisciplinary dialogic exploration of possible futures, e.g., pandemic response, climate change adaptation, etc.

This case study, along with any future development of 'rapid' scenario approaches, may help overcome the perception that scenario planning is always resource-intensive for participants, and therefore that 'rapid' variants may have increased appeal as a tool for use where policy must be developed to guide change for uncertain futures.

As a final note, the promising result of this specific case study can only be seen as a first step. There are regional limits to growth that are difficult to estimate with the limited type of qualitative assessments possible in this study. Greater elaboration, comparisons and quantitative modelling would be needed to make comprehensive policy roadmaps. While policy roadmaps are typically developed within a professional planning context, we would argue that this more detailed work would also benefit from the broader perspective that transdisciplinary collaboration brings. Such a future research agenda could also explore the potential of an educational approach within and across municipalities focused upon strategic sustainable development to help link sustainability science to policy action, thereby supporting the translation of the 'rapid' scenarios into detailed sustainability transformation policy.

Author Contributions: G.T. conceived and led the article, all authors were involved in co-writing the article; H.N. led the scenarios project, the scenario workshop facilitation was led by V.N., supported by H.N., S.B. and G.T.; the workshop description section borrows heavily from the post-workshop report (in Swedish) 'Scenarier för Blekinge $2050^{\prime}$ prepared by H.N., V.N., G.T. and S.B.; conceptualization and framing by J.B., J.A. and G.T.; evaluation interview by H.N.; review and editing by all authors. All authors have read and agreed to the published version of the manuscript.

Funding: Region Blekinge funded the workshop and part-funded the pre-workshop preparation and post-workshop report with additional time on the project supported through BTH faculty funding.

Acknowledgments: We gratefully acknowledge Jenny Rydquist from Region Blekinge for inviting us to work with Region Blekinge and for funding support; and Peter Schlyter, Blekinge Institute of Technology, for invaluable input to the study design. We also thank all other workshop support staff and stakeholders involved with this study.

Conflicts of Interest: Region Blekinge funded the workshop and played an active role in framing the day. The BTH research team independently prepared the post-workshop conclusions, scenarios and this paper. The funder (RB) played no role in the design of the study; in the collection, analyses, or interpretation of data; in the writing of the manuscript, or in the decision to publish the results. 


\section{Appendix A}

Table A1. List of participating stakeholder organizations.

\begin{tabular}{cc}
\hline Swedish Organization Name & English Translation \\
\hline Energikontor Sydost AB & Energy Agency Southeast \\
Länsstyrelsen Jönköping & County Administrative Board Jönköping \\
Länsstyrelsen Blekinge & County Administrative Board Blekinge \\
Karlshamns kommun & Karlshamn Municipality \\
Region Blekinge & Region Blekinge (regional authority) \\
Blekingetrafiken & Blekinge Public Transport Authority \\
Tillväxtverket & Sölvesborgs Municipality \\
Sölvesborgs kommun & Ronneby Municipality \\
Ronneby Kommun & Blekinge Institute of Technology \\
Blekinge tekniska högskola & Karlskrona Municipality \\
Karlskrona kommun & Openlab, Royal Institute of Technology \\
Openlab, Kungliga Tekniska Högskolan & Blekinge Archipelago \\
\hline
\end{tabular}

\section{Appendix B}

Summary of workshop activities:

- Pre-meeting with table facilitators that discussed ground rules and the workshop plan.

- First participant exercise: A five-minute real-time interactive 'mentimeter' exercise with all participants invited to use keywords to describe their initial thoughts relating to 'Attractive Blekinge' with results projected for the whole room to see.

- Framing of the day: International, national and regional goals introduced. Summaries of local visions captured in a word cloud. Description of the ABCD approach, sustainability challenges in Blekinge and presentation of speculative spatial mapping implications of future urban growth.

- Participants divided into eight break-out tables with a facilitator (5-8 people per table).

- Participant break-out exercise 1: group work in a World café style to capture positive and negative perceptions relating to 'Attractive Blekinge'.

○ Participant break-out exercise 2: scenario development corresponding to the four scenarios with pre-defined axes.

- There were four scenario development rounds so everyone could contribute to each of the scenarios (30 $\mathrm{min}+20 \mathrm{~min}+20 \mathrm{~min}+20 \mathrm{~min}$ ).

- When the discussion started to die out or slow down, the facilitators were provided with thematic cards on issues raised in earlier policy documents as discussion prompts. They could be taken one by one and related to the questions at hand.

$\bigcirc$ Group feedback: facilitators offered summary report on key factors arising, major conflicts, synergies and trade-offs. No repetition from other tables.

○ Wrap-up and next steps.

\section{References}

1. Volkery, A.; Ribeiro, T. Scenario planning in public policy: Understanding use, impacts and the role of institutional context factors. Technol. Forecast. Soc. Chang. 2009, 76, 1198-1207. [CrossRef]

2. Varum, C.A.; Melo, C. Directions in scenario planning literature-A review of the past decades. Futures 2010, 42, 355-369. [CrossRef]

3. Avin, U.; Goodspeed, R. Using Exploratory Scenarios in Planning Practice: A Spectrum of Approaches. J. Am. Plan. Assoc. 2020, 1-14. [CrossRef]

4. Chakraborty, A.; McMillan, A. Scenario planning for urban planners: Toward a practitioner's guide. J. Am. Plan. Assoc. 2015, 81, 18-29. [CrossRef] 
5. Broman, G.I.; Robèrt, K.-H. A framework for strategic sustainable development. J. Clean. Prod. 2017, 140, 17-31. [CrossRef]

6. Kajikawa, Y.; Tacoa, F.; Yamaguchi, K. Sustainability science: The changing landscape of sustainability research. Sustain. Sci. 2014, 9, 431-438. [CrossRef]

7. Lang, D.J.; Wiek, A.; Bergmann, M.; Stauffacher, M.; Martens, P.; Moll, P.; Swilling, M.; Thomas, C.J. Transdisciplinary research in sustainability science: Practice, principles, and challenges. Sustain. Sci. 2012, 7, 25-43. [CrossRef]

8. Lehtonen, A.; Salonen, A.; Cantell, H.; Riuttanen, L. A pedagogy of interconnectedness for encountering climate change as a wicked sustainability problem. J. Clean. Prod. 2018, 199, 860-867. [CrossRef]

9. Steffen, W.; Richardson, K.; Rockstrom, J.; Cornell, S.E.; Fetzer, I.; Bennett, E.M.; Biggs, R.; Carpenter, S.R.; de Vries, W.; de Wit, C.A.; et al. Planetary boundaries: Guiding human development on a changing planet. Science 2015, 347, 1259855. [CrossRef]

10. Rittel, H.W.J.; Webber, M.M. Dilemmas in a general theory of planning. Policy Sci. 1973, 4, 155-169. [CrossRef]

11. Levin, K.; Cashore, B.; Bernstein, S.; Auld, G. Overcoming the tragedy of super wicked problems: Constraining our future selves to ameliorate global climate change. Policy Sci. 2012, 45, 123-152. [CrossRef]

12. Levin-Keitel, M.; Mölders, T.; Othengrafen, F.; Ibendorf, J. Sustainability transitions and the spatial interface: Developing conceptual perspectives. Sustainability 2018, 10, 1880. [CrossRef]

13. United Nations. Adoption of the Paris Agreement [Internet]. In Framework Convention on Climate Change "Adoption of the Paris Agreement"; United Nations: Paris, France, 2015; Volume 21930. Available online: http://unfccc.int/resource/docs/2015/cop21/eng/109r01.pdf (accessed on 15 May 2020).

14. United Nations General Assembly. Transforming our world: The 2030 agenda for sustainable development. In Proceedings of the United Nations Sustainable Development Summit, New York, NY, USA, 25 September 2015.

15. United Nations. New Urban Agenda [Internet]. In Proceedings of the United Nations Conference on Housing and Sustainable Urban Development (Habitat III), Quito, Ecuador, 20 October 2016. Available online: http://habitat3.org/wp-content/uploads/NUA-English.pdf (accessed on 15 May 2020).

16. Sachs, J.; Schmidt-Traub, G.; Kroll, C.; Lafortune, G.; Fuller, G.; Woelm, F. The Sustainable Development Goals and COVID-19. Sustainable Development Report 2020; Cambridge University Press: Cambridge, UK, 2020.

17. Swedish Climate Policy Council. Klimatpolitiska Rådets Rapport; Swedish Climate Policy Council: Stockholm, Sweden, 2019.

18. Coenen, L.; Benneworth, P.; Truffer, B. Toward a spatial perspective on sustainability transitions. Res. Policy 2012, 41, 968-979. [CrossRef]

19. Cairns, G.; Wright, G.; Fairbrother, P.; Phillips, R. ‘Branching scenarios' seeking articulated action for regional regeneration-A case study of limited success. Technol. Forecast. Soc. Chang. 2017, 124, 189-202. [CrossRef]

20. Ehnert, F.; Kern, F.; Borgström, S.; Gorissen, L.; Maschmeyer, S.; Egermann, M. Urban sustainability transitions in a context of multi-level governance: A comparison of four European states. Environ. Innov. Soc. Transit. 2018, 26, 101-116. [CrossRef]

21. Polk, M. Achieving the promise of transdisciplinarity: A critical exploration of the relationship between transdisciplinary research and societal problem solving. Sustain. Sci. 2014, 9, 439-451. [CrossRef]

22. Brown, T. Design thinking. Harv. Bus. Rev. 2008, 86, 84-92.

23. Polk, M. Co-producing Knowledge for Sustainable Cities: Joining Forces for Change; Routledge: London, UK, 2015; 212p.

24. Ny, H.; Nikulina, V.; Thomson, G.; Borén, S. Scenarier för Blekinge 2050: En rapport inom projektet Strukturbild Blekinge 2.0; Blekinge Tekniska Högskola: Karlskrona, Sweden, 2019.

25. Innes, J.E.; Booher, D.E. Reframing public participation: Strategies for the 21st century. Plan. Theory Pract. 2004, 5, 419-436. [CrossRef]

26. Wiek, A.; Withycombe, L.; Redman, C.L. Key competencies in sustainability: A reference framework for academic program development. Sustain. Sci. 2011, 6, 203-218. [CrossRef]

27. Keuschnigg, M. Scaling trajectories of cities. Proc. Natl. Acad. Sci. USA 2019, 116, 13759-13761. [CrossRef]

28. Othengrafen, F.; Levin-Keitel, M. Planners between the chairs: How planners (do not) adapt to transformative practices. Urban Plan. 2019, 4, 111-125. [CrossRef] 
29. Fazey, I.; Schäpke, N.; Caniglia, G.; Patterson, J.; Hultman, J.; van Mierlo, B.; Säwe, F.; Wiek, A.; Wittmayer, J.; Aldunce, P.; et al. Ten essentials for action-oriented and second order energy transitions, transformations and climate change research. Energy Res. Soc. Sci. 2018, 40, 54-70. [CrossRef]

30. Bradbury, H.; Waddell, S.; O' Brien, K.; Apgar, M.; Teehankee, B.; Fazey, I. A call to Action Research for Transformations: The times demand it. Action Res. 2019, 17, 3-10. [CrossRef]

31. Bryant, J.; Thomson, G. Learning as a key leverage point for sustainability transformations: A case study of a local government in Perth, Western Australia. Sustain. Sci. 2020, 8, 103-119. [CrossRef]

32. Schoemaker, P.J.H. Scenario planning: A tool for strategic thinking. Sloan Manag. Rev. 1995, 36, 25-40.

33. Nikulina, V.; Lindal, J.L.; Baumann, H.; Simon, D.; Ny, H. Lost in translation: A framework for analysing complexity of co-production settings in relation to epistemic communities, linguistic diversities and culture. Futures 2019, 113, 102442. [CrossRef]

34. Hallding, K.; Eriksson, E.A.; Mobjörk, M.; Nilsson, M.; Alfredsson, E.; Skånberg, K.; Sonnsjö, H.; Benzie, M.; Carlsen, H.; Kemp-Benedict, E. Sweden in a World of Growing Uncertainties. Background report 10 to the Commission on the Future of Sweden; Government Offices of Sweden Prime Minister's Office: Stockholm, Sweden, 2013. Available online: https://www.regeringen.se/49b6d0/contentassets/4f37c6b273974f1cb343e4e5442f3f21/ sweden-in-a-world-of-growing-uncertainties (accessed on 22 June 2020).

35. Keough, S.M.; Shanahan, K.J. Scenario Planning: Toward a More Complete Model for Practice. Adv. Dev. Hum. Resour. 2008, 10, 166-178. [CrossRef]

36. Nikulina, V.; Simon, D.; Ny, H.; Baumann, H. Context-Adapted Urban Planning for Rapid Transitioning of Personal Mobility towards Sustainability: A Systematic Literature Review. Sustainability 2019, 11, 1007. [CrossRef]

37. Börjeson, L.; Höjer, M.; Dreborg, K.-H.; Ekvall, T.; Finnveden, G. Scenario types and techniques: Towards a user's guide. Futures 2006, 38, 723-739. [CrossRef]

38. França, C.L. Business Model Design for Strategic Sustainable Development; Blekinge Institute of Technology: Karlskrona, Sweden, 2017.

39. Ny, H.; Borén, S.; Nurhadi, L.; Schulte, J.; Robért, K.-H.; Broman, G. Roadmap 2030 (No. 2017:01); Blekinge Institute of Technology: Karlskrona, Sweden, 2017.

40. Viszlay, Z.; Mumme, J.; Hagedorn, H. Planning for Sustainability in Swedish Municipalities: A Strategic Approach; Blekinge Institute of Technology: Karlskrona, Sweden, 2017.

41. Borén, S.; Nurhadi, L.; Ny, H.; Andersson, M.; Nilsson, S.; Lööf, J. GreenCharge: Demotest i Fält Med Elbuss; Blekinge Tekniska Högskola: Karlskrona, Sweden, 2015. Available online: https://www.diva-portal.org/ smash/get/diva2:882216/FULLTEXT01.pdf (accessed on 26 June 2020).

42. Robèrt, K.; Schmidt-Bleek, B.; de Larderel, A.; Basile, G.; Jansen, J.L.; Kuehr, R.; Thomas, P.P.; Suzuki, M.; Hawken, P.; Wackernagel, M. Strategic sustainable development—selection, design and synergies of applied tools. J. Clean. Prod. 2002, 10, 197-214. [CrossRef]

43. Region Blekinge. Region Blekinge webpage: Structural image Blekinge [Internet]. Available online: https://regionblekinge.se/utveckling-och-projekt/regional-utvecklingsstrategi/satsningar-som-utvecklarblekinge/strukturbild-blekinge.html (accessed on 22 June 2020).

44. McCauley, C.D.; Drath, W.H.; Palus, C.J.; O'Connor, P.M.G.; Baker, B.A. The use of constructive-developmental theory to advance the understanding of leadership. Leadersh, Q. 2006, 17, 634-653. [CrossRef]

45. Huang, H.B. What is good action research? Why the resurgent interest? Action Res. 2010, 8, 93-109. [CrossRef]

46. Upham, P.; Carney, S.; Klapper, R. Scaffolding, software and scenarios: Applying Bruner's learning theory to energy scenario development with the public. Technol. Forecast. Soc. Chang. 2014, 81, 131-142. [CrossRef]

47. Thomson, G.; Newman, P. Cities and the Anthropocene: Urban governance for the new era of regenerative cities. Urban Stud. 2018, 57, 1502-1519. [CrossRef]

48. Wik, M.; Ljungquist, S. Growth Priorities for Blekinge 2021-2027. In A Report to the Swedish Ministry of Enterprise and Innovation; Report No. 2019/00507; Blekinge Tekniska Högskola: Karlskrona, Sweden, 2019.

49. Borén, S.; Nurhadi, L.; Ny, H.; Robèrt, K.-H.; Broman, G.; Trygg, L. A strategic approach to sustainable transport system development-Part 2: The case of a vision for electric vehicle systems in southeast Sweden. J. Clean. Prod. 2017, 140, 62-71. [CrossRef]

50. Newman, P.; Kenworthy, J. The End of Automobile Dependence: How Cities are Moving Beyond Car-Based Planning; Island Press: Washington, DC, USA, 2015. 
51. Thomson, G.; Newman, P. Urban fabrics and urban metabolism—from sustainable to regenerative cities. Resour. Conserv. Recycl. 2018, 132, 218-229. [CrossRef]

52. Bracken, L.J.; Bulkeley, H.A.; Whitman, G. Transdisciplinary research: Understanding the stakeholder perspective. J. Environ. Plan. Manag. 2015, 58, 1291-1308. [CrossRef]

53. Lang, D.J.; Wiek, A.; von Wehrden, H. Bridging divides in sustainability science. Sustain. Sci. 2017, 12, 875-879. [CrossRef]

54. Smith, A.; Stirling, A. Social-Ecological Resilience and Socio-Technical Transitions: Critical Issues for Sustainability Governance; STEPS Centre: Brighton, UK, 2008.

55. Gaziulusoy, I.; Ryan, C. Roles of design in sustainability transitions projects: A case study of Visions and Pathways 2040 project from Australia. J. Clean. Prod. 2017, 162, 1297-1307. [CrossRef]

56. Lawrence, R. Advances in transdisciplinarity: Epistemologies, methodologies and processes. Futures 2015, 65, 1-9. [CrossRef]

57. Robèrt, K.-H.; Borén, S.; Ny, H.; Broman, G. A strategic approach to sustainable transport system development-Part 1: Attempting a generic community planning process model. J. Clean. Prod. 2017, 140, 53-61. [CrossRef]

(C) 2020 by the authors. Licensee MDPI, Basel, Switzerland. This article is an open access article distributed under the terms and conditions of the Creative Commons Attribution (CC BY) license (http://creativecommons.org/licenses/by/4.0/). 